\title{
HUBUNGAN KADAR HB PRE TRANFUSI DENGAN KUALITAS HIDUP PENDERITA TALASEMIA DI RSUD Dr. Hi ABDUL MOELOEK PROVINSI LAMPUNG
}

\author{
Dea Prasetya \\ Pendidikan Dokter, Fakultas Kedokteran, Universitas Malahayati \\ Email koresnponensi: Sadegad10@yahoo.com
}

\begin{abstract}
THE RELATIONSHIP OF PRE-TRANSFUSION HB LEVEL WITH QUALITY OF LIFE OF THALASEMIA PATIENTS IN RSUD Dr. Hi ABDUL MOELOEK, LAMPUNG PROVINCE
\end{abstract}

Background: Thalassemia is a chronic disease that can significantly affect the patient's quality of life, which is caused by the disease itself and the effects of the therapy given. Patients with thalassemia in Dr H Abdoel Moeloek Hospital Lampung Province from year to year showed an increasing trend, namely in 2012 as many as 75 people, in 2013 as many as 87 people and in 2014 as many as 102 people.

Purpose: To determine the relationship between $\mathrm{Hb}$ levels before transfusion with the quality of life of thalassemia patients. Hi Abdul Moeloek Lampung Province

Research Methods: This type of research is a quantitative, analytical observation design, with a cross-sectional design. The study population was all pediatric thalassemia patients at Dr. Hospital. Hi Abdul Moeloek, Lampung Province for the period January - October 2019 with a total of 146 patients. The sample is 60 people. Collecting data using observation sheets and questionnaires. The data analysis technique used regression test.

Results: The average distribution of $\mathrm{Hb}$ levels before transfusion of the research subjects was 7.11 with the lowest value being 6.8 and the highest being 7.4. The distribution of the average quality of life of the subjects of this study was 60.72 with the lowest value of 27 and the highest 93. There was a significant relationship between Pre-Transfusion $\mathrm{Hb}$ Levels and Quality of Life of Thalassemia Patients at Abdul Moeloek Hospital Bandar Lampung in 2019 (p value 0.000 ).

Conclusion: There is a significant relationship between $\mathrm{Hb}$ levels before transfusion with Quality of Life of Thalassemia Patients. It is recommended to monitor $\mathrm{Hb}$ levels before transfusion and comply with transfusions and consume iron chelation regularly so that the growth of their children can be normal like other children.

Keywords: Hb levels before transfusion, Quality of Life, Thalassemia Patients

INTISARI: HUBUNGAN KADAR HB PRE TRANFUSI DENGAN KUALITAS HIDUP PENDERITA TALASEMIA DI RSUD Dr. Hi ABDUL MOELOEK PROVINSI LAMPUNG

Latar Belakang : Thalasemia adalah salah satu penyakit kronis yang dapat mempengaruhi kualitas hidup penderita secara nyata, yang diakibatkan penyakitnya sendiri maupun efek terapi yang diberikan. Penderita thalasemia di RSUD Dr H Abdoel Moeloek Provinsi Lampung, dari tahun ketahun menunjukkan 
trend mengalami kenaikan, yaitu tahun 2012 berjumlah 75 orang, tahun 2013 berjumlah 87 orang dan tahun 2014 tercatat 102 orang.

Tujuan penelitian: Diketahui hubungan kadar $\mathrm{Hb}$ Pre Transfusi dengan kualitas hidup penderita Talasemia Di RSUD Dr. Hi Abdul Moeloek Provinsi Lampung

Metode Penelitian : Jenis penelitian kuantitatif, rancangan observasi analitik, dengan desain cross sectional. Populasi penelitian adalah semua pasien Talasemia anak di RSUD Dr. Hi Abdul Moeloek Provinsi Lampung periode Januari - Oktober 2019 sejumlah 146 pasien. Sampel 60 orang. Pengambilan data menggunakan lembar observasi dan kuesioner. Teknik analisis data menggunakan uji regresi.

Hasil penelitian : Distribusi rata-rata kadar $\mathrm{Hb}$ Pre tranfusi subyek penelitian ini adalah 7,11 dengan nilai terendah 6,8 dan tertinggi 7.4. Distribusi rata-rata kualitas hidup subyek penelitian ini adalah 60,72 dengan nilai terendah 27 dan tertinggi 93. Ada hubungan antara hubungan yang signifikan antara Kadar Hb Pre Transfusi Dengan Kualitas Hidup Penderita Talasemia di Rumah Sakit Abdul Moeloek Bandar Lampung tahun 2019 (p value 0,000).

Kesimpulan : Ada hubungan antara hubungan yang signifikan antara Kadar $\mathrm{Hb}$ Pre Transfusi Dengan Kualitas Hidup Penderita Talasemia. Disarankan agar melakukan pemantauan terhadap Kadar Hb Pre Transfusi dan patuh menjalani tranfusi serta mengkonsumsi kelasi besi secara teratur agar pertumbuhan anaknya dapat normal seperti anak-anak lainnya.

Kata Kunci : Kadar Hb Pre Transfusi, Kualitas Hidup, Penderita Talasemia

\section{PENDAHULUAN}

Thalasemia adalah penyakit keturunan karena adanya kelainan darah yang dapat berdampak pada berbagai organ akibat penyakitnya sendiri atau pengobatan yang diberikan. Penyakit thalasemia ditemukan di seluruh dunia dan di beberapa negara tropis merupakan prevalensi gen thalasemia tertinggi (TIF, 2008). Penduduk dunia mempunyai gen thalasemia kurang lebih $3 \%$, dan kejadian tertinggi adalah di Asia yaitu sampai dengan 40\% kasus (Rund, 2015). Sedangkan pembawa sifat thalasemia mencapai 55 juta orang terdapat di wilayah Asia Tenggara (Thavorncharoensap , et al 2010).

Pada tahun 2001 World Health Organization (WHO) melaporkan bahwa sekitar $7 \%$ populasi penduduk di dunia bersifat carrier dan sekitar 300.000 sampai 500.000 bayi lahir dengan talasemia setiap tahunnya. Salah satu negara yang memiliki penduduk pembawa thalasemia adalah di Indonesia, dengan frekuensi pembawa thalasemia adalah sekitar 3-8\%, dan untuk beberapa daerah di Indonesia mencapai $10 \%$, yang berarti bahwa 3-8 dari 100 penduduk merupakan pembawa gen thalasemia, dengan angka kelahiran rata rata $23 \%$ dengan jumlah populasi penduduk sebanyak 240 juta, sehingga diperkirakan akan lahir 3000 bayi pembawa gen thalasemia tiap tahunnya (Bulan, 2009).

Menurut hasil Riset Kesehatan Dasar (Riskesda) pada tahun 2012, menunjukkan bahwa prevalensi talasemia di Indonesia sebesar 0,1\%. Berdasarkan Data Pusat thalasemia Departemen IImu kesehatan anak (IKA) Fakultas Kedokteran

Universitas Indonesia (FKUI) Rumah Sakit Cipto Mangun Kusumo hingga akhir tahun 2008 terdaftar $50 \%$ thalasemia B, 48,2\% thalasemia B/ $\mathrm{Hb}-\mathrm{E}$ dan $1,8 \%$ pasien thalasemia $\mathrm{a}$, dengan jumlah pasien sebanyak 1.455 pasien.

Thalasemia adalah salah satu 
penyakit kronis yang dapat mempengaruhi kualitas hidup penderita secara nyata, yang diakibatkan penyakitnya sendiri maupun efek terapi yang diberikan. Selain itu juga dapat mengganggu tidak hanya secara fisik namun juga fungsi sosial dan emosionalnya. Anak yang menderita Thalasemia secara umum akan memperlihatkan gejala depresi, cemas, gangguan psikososial, dan gangguan fungsi sekolah. Masalah tersebut juga dapat dialami oleh anggota keluarga yaitu orang tua maupun saudara dari penderita Thalasemia, dimana mereka akan merasa sedih, kecewa, putus asa, stress, depresi dan cemas terhadap kesehatan dan masa depan penderita selanjutnya. Sehingga untuk menindaklanjuti kedua kondisi ini, perlu dilakukan penilaian terhadap kualitas hidup anak penderita Talasemia dan juga anggota keluarga penderita guna menentukan tindakan yang dapat dilakukan untuk mendukung perbaikan kualitas hidup anak penderita Talasemia.

Thalasemia beta mayor sendiri sebagai salah satu penyakit genetik yang akan diderita seumur hidup, akan membawa masalah yang cukup banyak bagi penderitanya, baik sebagai dampak dari proses penyakitnya itu sendiri ataupun karena dari pengobatannya. Penyakit thalasemia terutama thalasemia $\beta$ termasuk penyakit yang memerlukan pengobatan dan perawatan yang berkelanjutan diantaranya yaitu dengan transfusi secara terus menerus dan terapi kelasi besi (Bulan, 2009).

Kondisi kronik yang dialami oleh anak bisa dapat berpengaruh terhadap kondisi fisik, psikis dan sosial karenapada periode tersebut anak sedang mengalami proses maturasi fisik dan perkembangan yang setiap tahapannya memiliki tugas masing-masing. Anak juga dituntut untuk dapat memenuhi tugas-tugas tersebut yang pada akhirnya akan mempengaruhi kualitas hidup anak. Ismail et al (2006) menemukan bahwa dampak negatif pada fisik, selain masalah emosional juga pada fungsi sekolah pada pasien thalasemia beta mayor yang lebih buruk dibandingkan anak sehat. Dengan demikian maka sangat jelas bahwa kualitas hidup merupakan hal yang perlu dipertimbangkan dan juga menjadi hal yang penting dalam suatu efek dalam pemberian transfusi darah dan pemberian terapi kelasi besi sebagai pengobatan pada anak dengan thalasemia. Karena kondisi tersebut menyebabkan kualitas hidup anak umumnya menjadi rendah.

Hingga saat ini belum diketahui secara pasti faktor penyebab turunnya kualitas hidup pada anak baik secara sendiri-sendiri maupun bersama-sama, demikian juga faktorfaktor yang mempengaruhi kualitas hidup anak thalassemia beta mayor yang sangat kompleks dan multifaktorial akibat pengaruh dari penyakitnya sendiri maupun pengobatannya. Hal inilah yang membuat pengukuran kualitas hidup kesehatan anak dengan thalassemia mayor menjadi penting sebagai penilaian biopsikososial secara utuh.

Penderita thalasemia di RSUD Dr H Abdoel Moeloek Provinsi Lampung, dari tahun ketahun menunjukkan trend mengalami kenaikan, yaitu tahun 2012 berjumlah 75 orang, tahun 2013 berjumlah 87 orang dan tahun 2014 tercatat 102 orang (Rekam Medik RSUAM, 2018). Berdasarkan data tersebut, maka penulis tertarik untuk meneliti tentang hubungan kadar $\mathrm{Hb}$ Pre Transfusi dengan kualitas hidup penderita Talasemia Di RSAM Bandar Lampung Tahun 2019.

\section{METODE}

Jenis penelitian ini menggunakan metode penelitian analitik yaitu peneliti menggali bagaimana dan mengapa fenomena 
kesehatan itu terjadi. Kemudian melakukan analisa dinamika korelasi antara fenomena atau antara faktor risiko dengan faktor efek (Notoatmodjo, 2012). Pada penelitian ini sampel diambil dari seluruh populasi dengan menggunakan kuesioner sebagai alat pengumpulan data.

Jenis penelitian ini adalah penelitian observasi analitik, dengan desain cross sectional. Cross sectional adalah suatu penelitian untuk mempelajari dinamika korelasi antara faktor-faktor risiko dengan efek, dengan cara pendekatan, observasi atau pengumpulan data sekaligus pada suatu saat (point time approach) (Notoatmodjo, 2012). Penelitian ini untuk menjelaskan hubungan kadar $\mathrm{Hb}$ Pre Transfusi dengan kualitas hidup penderita Talasemia Di RSUD Dr. Hi Abdul Moeloek Provinsi Lampung Tahun 2019.

Tempat dan waktu penelitian sangat berpengaruh terhadap hasil yang diperoleh dalam penelitian. Pemilihan tempat penelitian harus disesuaikan dengan tujuan yang ingin dicapai dalam penelitian, sehingga tempat ditentukan benarbenar menggambarkan kondisi informan yang

sesungguhnya. Tempat penelitian adalah tempat interaksi informan dengan lingkungannya yang akan membangun pengalaman hidupnya (Saryono \& Anggraeni, 2015).

Tempat Penelitian

Penelitian ini dilakukan di RSUD Dr. $\mathrm{Hi}$ Abdul Moeloek Provinsi Lampung terhadap pasien penderita thalasemia beta mayor dan telah memenuhi kriteria penelitian yang telah ditetapkan oleh peneliti.

Waktu Penelitian Penelitian ini dilakukan pada bulan Desember 2019

\section{HASIL DAN PEMBAHASAN}

Penelitian dilakukan pada bulan Januari 2020 dengan mengambil data dari rekam medik pasien penderita Thalasemia di Rumah Sakit Umum Daerah Dr. H. Abdul Moeloek Provinsi Lampung. Didapatkan 60 subjek penelitian dari 115 pasien penderita Thalasemia.

\section{Analisis Univariat}

Analisis univariat yang dilakukan untuk menjelaskan atau mendeskripsikan karakteristik setiap variabel penelitian. Pada umumnya dalam analisis ini hanya menghasilkan distribsi frekuensi dan presentase dari tiap variabelnya (Notoatmodjo, 2015).

\section{Karakteristik Responden Jenis Kelamin}

Tabel 1

Distribusi frekuensi Jenis Kelamin pada pasien Thalasemia di Rumah Sakit Abdul Moeloek Bandar Lampung tahun 2019

\begin{tabular}{lcc}
\hline \multicolumn{1}{c}{ Jenis Kelamin } & Jumlah & Presentase \% \\
\hline Perempuan & 31 & $51.7 \%$ \\
Laki-Laki & 29 & $48.3 \%$ \\
\hline Total & 60 & $100.0 \%$ \\
\hline
\end{tabular}

Berdasarkan tabel 1 di atas didapatkan jenis kelamin pasien Thalasemia di Rumah Sakit Abdul
Moeloek Provinsi Lampung tahun 2019 sebagian besar adalah perempuan yaitu sebanyak 31 orang $(51,7 \%)$. 
Usia

Tabel 2

Distribusi frekuensi Usia pada pasien Thalasemia di Rumah Sakit Abdul Moeloek Provinsi Lampung tahun 2019

\begin{tabular}{|c|c|c|}
\hline Usia & Jumlah & Presentase $\%$ \\
\hline > 5 Tahun & 42 & $70.0 \%$ \\
\hline$\leq 5$ Tahun & 18 & 30.0 \% \\
\hline Total & 60 & $100.0 \%$ \\
\hline
\end{tabular}

Berdasarkan tabel 2 di atas didapatkan usia pada pasien Thalasemia di Rumah Sakit Abdul
Moeloek Provinsi Lampung tahun 2019 sebagian besar adalah $>5$ tahun yaitu sebanyak 42 orang $(70,0 \%)$.

\section{Rata-rata Distribusi Kadar Hb Pasien Thalasemia}

Tabel 3

Rata-rata Kadar Hb pada pasien Thalasemia di Rumah Sakit Abdul Moeloek Provinsi Lampung tahun 2019

\begin{tabular}{ccccc}
\hline Variabel & Mean & SD & Min-Max & $\mathrm{Cl} 95 \%$ \\
\hline Kadar HB & 7.11 & 0.2 & $6,8-7,4$ & $7,06-7,16$ \\
\hline
\end{tabular}

Berdasarkan tabel 4.3 di atas rata-rata kadar $\mathrm{Hb}$ Pre tranfusi subyek penelitian ini adalah 7,11 dengan nilai terendah 6,8 dan tertinggi 7.4 .

Rata-rata Kualitas Hidup

Tabel 4

Rata-rata Kualitas Hidup pada pasien Thalasemia di Rumah Sakit Abdul Moeloek Provinsi Lampung tahun 2019

\begin{tabular}{ccccccc}
\hline Variabel & N & $\begin{array}{c}\text { Fungsi } \\
\text { fisik }\end{array}$ & $\begin{array}{c}\text { Fungsi } \\
\text { emosional }\end{array}$ & $\begin{array}{c}\text { Fungsi } \\
\text { sosial }\end{array}$ & $\begin{array}{c}\text { Fungsi } \\
\text { sekolah }\end{array}$ & $\begin{array}{c}\text { Skor } \\
\text { fungsi } \\
\text { psikososial }\end{array}$ \\
\hline $\begin{array}{c}\text { Kualitas } \\
\text { Hidup }\end{array}$ & $\begin{array}{c}6 \\
0\end{array}$ & 47.21 & 56.98 & 54.25 & 52.30 & 54.5 \\
\hline
\end{tabular}

Berdasarkan tabel 4.4 di atas rata-rata kualitas hidup subyek penelitian ini adalah 53,23, meliputi

\section{Analisis Bivariat}

Setelah diketahui karakteristik masing-masing variabel dapat diteruskan analisis lebih lanjut. apabila diinginkan analisis hubungan antara dua variabel, maka analisis dilanjutkan pada tingkat bivariat. Untuk mengetahui hubungan dua skor tertinggi pada fungsi emosional yaitu 56,98 dan terendah pada fungsi fisik yaitu 47,21.

variabel tersebut biasanya digunakan pengujian statistik. Jenis uji statistik yang digunakan sangat tergantung jenis data/variabel yang dihubungkan. Pada penelitian ini analisis bivariat yang digunakan adalah uji regresi karena kedua variabel merupakan data kategorik. 
Tabel 5

Morbalitas

\begin{tabular}{cccccc}
\hline ANOVA & N & Sig & Df & F & Mean \\
\hline Kadar Hb Pre & \multirow{2}{*}{60} & \multirow{2}{*}{0,000} & 58 & \multirow{2}{*}{39,870} & 250,202 \\
Transfusi & & & 59 & & 10294,456 \\
\hline
\end{tabular}

Tabel 6

Hubungan Kadar Hb Pre Transfusi Dengan Kualitas Hidup Penderita Talasemia Di RSUD Dr. Hi Abdul Moeloek Provinsi Lampung Tahun 2019

\begin{tabular}{lcclc}
\hline & R & R Square & Persamaan garis & P value \\
\hline $\begin{array}{l}\text { Kadar Hb Pre } \\
\text { Transfusi }\end{array}$ & 0,638 & 0,407 & $\begin{array}{l}\text { Kualitas Hidup }=409,468 \\
+66,13^{*} \mathrm{HB} \text { pretranfusi }\end{array}$ & 0,000 \\
\hline
\end{tabular}

Hubungan Kadar $\mathrm{Hb}$ Pre Transfusi Dengan Kualitas Hidup Penderita Talasemia menunjukkan hubungan kuat $(r=0,638)$ dan berpola positif artinya semakin bertambah kadar $\mathrm{Hb}$ penderita talasemia semakin besar kualitas hidupnya. Nilai koefisien dengan determinasi 0,407 artinya, persamaan garis regresi yang kita

\section{KESIMPULAN}

1. Distribusi rata-rata kadar $\mathrm{Hb}$ Pre tranfusi subyek penelitian ini adalah 7,11 dengan nilai terendah 6,8 dan tertinggi 7.4.

2. Distribusi rata-rata kualitas hidup subyek penelitian ini adalah 60,72 dengan nilai terendah 27 dan tertinggi 93.

3. Ada hubungan antara hubungan yang signifikan antara Kadar $\mathrm{Hb}$ Pre Transfusi Dengan Kualitas Hidup Penderita Talasemia di Rumah Sakit Abdul Moeloek Bandar Lampung tahun 2019 (p value 0,000 ).

\section{SARAN}

1. Agar melakukan pemantauan terhadap Kadar Hb Pre Transfusi dan patuh menjalani tranfusi serta mengkonsumsi kelasi besi secara teratur agar pertumbuhan anaknya dapat normal seperti anak-anak lainnya peroleh dapat menerangkan 40,7\% variasi kadar $\mathrm{Hb}$ pre transfusi atau persamaan garis yang diperoleh cukup baik untuk menjelaskan variabel kualitas hidup. Hasil uji statistik didapatkan ada hubungan yang signifikan antara Kadar $\mathrm{Hb}$ Pre Transfusi Dengan Kualitas Hidup Penderita Talasemia $(p<0,005)$.

2. Diharapkan bagi peneliti selanjutnya untuk lebih memperhatikan data rekam medik tentang faktor-faktor lain yang berhubungan dengan kualitas hidup penderita talasemia

\section{DAFTAR PUSTAKA}

Alymara, V., Bourantas, D., Chaidos, A., Bouranta, P., Gouva, M., Vassou, A. et al. (2004). Effectiveness and Safety of Combined Iron-Chelation Therapy with Deferoxamine and Deferiprone. The Hematology Journal. 5:475479.

Atmakusuma, D. (2009). Thalassemia:Manifestasi Klinis, Pendekatan Diagnosis, dan Thalassemia Intermedia. Dalam Sudoyo, A.W., Setiyohadi, B., Alwi, I., 
Simadibra, M., Setiati, S. Buku Ajar Ilmu Penyakit Dalam edisis V. Jakarta: Pusat Penerbitan Ilmu Penyakit Dalam, hal 1387-1393.

Bakr, A.,Al-Tonbary, Y., Osman, G., El-Ashry, R. (2014). Renal Complications of BetaThalassemia Major in Children.Am J Blood Res. 4(1):1-6.

Cappellini, M. D. (2012). Goldman Cecil Medicine. Elsavier, 10601066.

Celc, A., Laura, M., Mariagrazia, F., Franco, B., Angela, C., Marcello, C. et al., (2011). TheManagement of Iron Chelation Therapy: Preliminary Data from a National Registry of Thalassaemic

Patients. Hindawi Publishing Corporation Anemia vol 2011:1-7.

Chaudhary, P., Pullarkat, V. (2013). Deferasirox: appraisal of safety and efficacy in longterm therapy. $\underline{\mathrm{J} \text { Blood }}$ Med. 5(4):101-10.

Cianciulli, P. (2009). Iron Chelation Therapy in Thalassemia Syndromes. Medit J Hemat Infect Dis. 1 (1). Ferri, F. F. 2015. Ferri's Clinical Advisor . Elsevier, hal 1156-1157.

Gomber, S., Saxena, R., Madan, N. (2004). Comparative Efficacy of Desferrioxamine, Deferiprone and in Combination on Iron Chelation in Thalassemic Children. Indian Pediatrics. 41:21-27.

Gomber, S., Saxena, R., Madan, N. (2004). Comparative Efficacy of Desferrioxamine, Deferiprone and in Combination on Iron Chelation in Thalassemic Children. Indian Pediatrics. 41:21-27.

Guidelines for the Clinical Care Of Patient with Thalassemia in
Canada. (2009). Anemia Institute for Research \& Education. Canada: Thalassemia Foundation of Canada

Health Technology Assessment Indonesia. (2009). Pencegahan Thalasemia. Dirjen Bina Pelayanan Medik Kementrian Kesehatan Republik Indonesia. Ibrahiem, O.A., Thabet, A.F. (2013). Deferasirox Versus Deferoxiamine for the Treatment of Transfusional Iron Overload in Patients with $B$-Thalassemia Major. Ibnosina J Med BS. 6(1):14-18.

Jamuar, S. S., Lai, A. H. M. (2012). Safety and Efficacy of Iron Chelation Therapy with Deferiprone in Patients with Transfusion-Dependent Thalassemia. Ther Adv Hematol. 3(5):299-307.

Jimmy, B., Jose, J. (2011). Patient Medication Adherence: Measures in Daily Practice. Oman Medical Journal. 26 (3):155-159.

Kidson-Gerber, G., Francis, S., Linderman, R. (2008). Management and Clinical Outcomes of Transfusiondependent Thalassaemia Major in an Australian Tertiary Referral Clinic. MJA. 188;2.

Kremastinos, DT., Farmakis, D., Aessopos, A., Hahalis, G., Hamodraka, E., Tsiapras, D. et al., (2010). B-thalassemia Cardiomyopathy History, Present Considerations, and Future Perspectives. Circ Heart Fail. 3:451-458.

Mashhadi, M.A., Rezvani, A.R., Naderi, M., Moghaddam, E. M. (2011). The Best Iron Therapy in Mayor Thalassemia Patients is Combination of Desferrioxamine and Deferiprone. International Journal of Hrmatology 
TAHUN [MANUJU: MALAHAYATI NURSING JOURNAL, P- ISSN: 2655-2728

Oncology and Stem Cell Research. 5(2):19-22.

Mishra, A.K., Tiwari, A. (2013). Iron Overload in Beta Thalassaemia Major and Intermedia Patients. MAEDICA -A Journal of Clinical Medicine. 8 (4):328332.

Palit, S., Bhuiyan, R.H., Aklima, J., Emran, T.B., Dash, R. (2012). A
Study of The Prevalence of Thalassemia and its Correlation With Liver Function Test in Different Age and Sex Group in the Chittagong District of Bangladesh. Journal of basic and clinical pharmacy. 3 (4): 352-357. 